\title{
Technique for retrospective respiratory and cardiac-gated phase contrast flow measurements
}

\author{
Ashley G Anderson ${ }^{1 *}$, Eric M Schrauben ${ }^{1}$, Kevin Johnson ${ }^{1}$, Oliver Wieben ${ }^{1,2}$ \\ From 15th Annual SCMR Scientific Sessions \\ Orlando, FL, USA. 2-5 February 2012
}

\begin{abstract}
Summary
A technique for evaluation of respiratory impact on cardiac-gated phase contrast flow acquisitions is proposed. An example study was performed showing the effect of active respiration on CSF flow through the spinal canal.
\end{abstract}

\section{Background}

The effect of the respiratory cycle on flow is well documented for cerebrospinal venous return [1] and CSF flow [2]. However, cranial phase contrast (PC) MR flow measurements neglect the influence of respiration. Breath-held acquisitions are possible, but mask physiological flow changes that occur during active respiration. Here we demonstrate a technique to evaluate the effects of active respiration on CSF flow measurements throughout the cardiac cycle for 2 respiration states.

\section{Methods}

Our approach relies on pseudo-random sampling of radial projections, which allows reconstruction of subsets with little artifact due to even filling of k-space (Fig. 1a). Cardiac triggers and respiratory position are recorded throughout the acquisition. Each projection then has a corresponding cardiac position (time since last trigger) and respiratory position. In the current implementation, all projections are sorted into 2 respiratory phases based on the median respiratory position. Each phase corresponds to the plateau surrounding endinspiration or -expiration. Each respiratory phase is represented by a cardiac gated image series that is reconstructed using a temporal filtering similar to view sharing in Cartesian acquisitions [3].

Three volunteers were scanned on a clinical $3 \mathrm{~T}$ system with 2D radial $\mathrm{PC}$ acquisitions [4] between the $\mathrm{C} 2$ and $\mathrm{C} 3$ vertebrae: $\mathrm{TR} / \mathrm{TE}=9.4 / 6.1 \mathrm{~ms}$, tip $=5^{\circ}$, resolution $=0.9 \times 0.9 \times 5 \mathrm{~mm}$, and Venc $=8 \mathrm{~cm} / \mathrm{s}$. Data were acquired during inspiration and expiration breath holds (1500 projections, $30 \mathrm{~s}$ ), and during regular free and deep breathing (8000 projections, 2:32 min). Triggering was accomplished with pulse oximeter and bellow signals.

\section{Results}

Fig. 2 shows the resulting flow waveforms acquired during deep breathing for two volunteers. Though the waveforms show variation, the trend of increased flow during inspiration holds in both examples. Average forward (Qf), reverse (Qr), and net (Qnet) flow were calculated for both phases in the free breathing scans. For the inspiration phase, these values were: $\mathrm{Qf}=3.06, \mathrm{Qr}=$ 1.53 , and Qnet $=1.53 \mathrm{ml} / \mathrm{min}$. For the bin surrounding end-expiration, these values were: $\mathrm{Qf}=2.53, \mathrm{Qr}=2.02$, Qnet $=0.51 \mathrm{ml} / \mathrm{min}$.

\section{Conclusions}

This study shows the feasibility of double retrospectively gated PC MR imaging for assessing flow in respiratory phases. The reconstruction scheme can be easily adjusted to capture additional respiratory phases at the expense of additional scan time. Our initial results demonstrate changes in CSF flow due to respirator phase, namely an overall increase in forward flow, as well as a decrease in reverse flow, leading to a significant increase in net flow during inspiration. This method can also be used to assessing venous and other flow affected by respiration.

\section{Funding}

NIH NHLBI R01HL072260. 

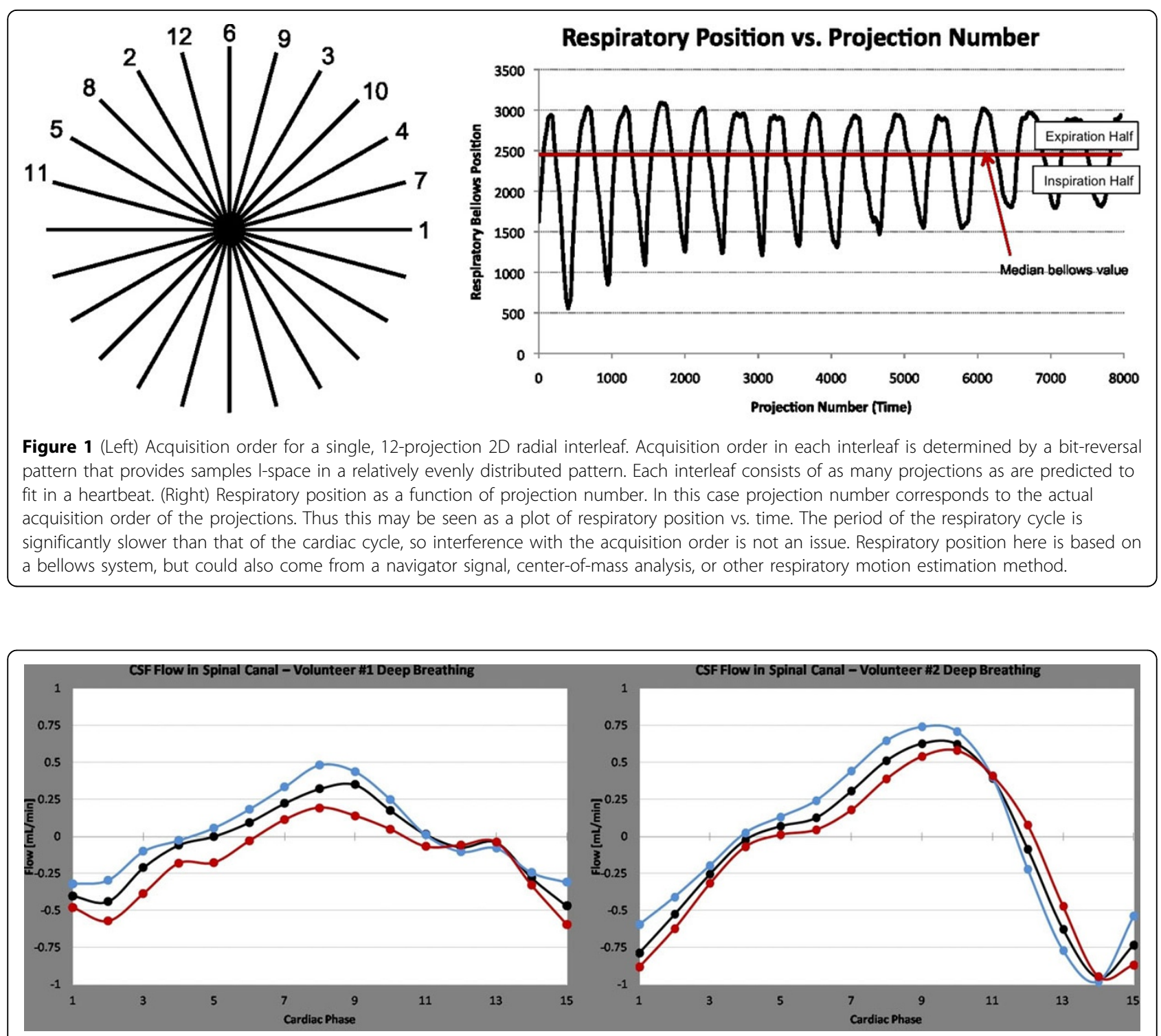

Figure 2 - CSF flow through the spinal cord for two volunteers during deep breathing. Three curves are shown for each volunteer, all measured from the same acquisition. Each chart depicts the flow from the respiratory phase surrounding inspiration (red) and expiration (blue) as well as the average flow measured without respiratory binning (black). Note the increase in flow in the inspiration phase, which corresponds to a decrease in thoracic pressure.

Author details

'Medical Physics, University of Wisconsin - Madison, Madison, WI, USA.

${ }^{2}$ Radiology, University of Wisconsin - Madison, Madison, WI, USA.

Published: 1 February 2012

\section{References}

1. O'Connell : Brain. 1943

2. Nordenstrom, et al: AJR. 1965

3. Liu, et al: IEEE TMI. 2006.

4. Barger, et al: MRM. 2000, 43(4)

doi:10.1186/1532-429X-14-S1-W26

Cite this article as: Anderson et al.: Technique for retrospective respiratory and cardiac-gated phase contrast flow measurements. Journal of Cardiovascular Magnetic Resonance 2012 14(Suppl 1):W26.
Submit your next manuscript to BioMed Central and take full advantage of:

- Convenient online submission

- Thorough peer review

- No space constraints or color figure charges

- Immediate publication on acceptance

- Inclusion in PubMed, CAS, Scopus and Google Scholar

- Research which is freely available for redistribution 